\title{
Impact of improved air quality on the future evolution of climate
}

\author{
G. P. Brasseur and E. Roeckner \\ Max Planck Institute for Meteorology, Hamburg, Germany \\ Received 24 June 2005; revised 31 August 2005; accepted 6 October 2005; published 6 December 2005.
}

[1] Calculations performed with the Hamburg Climate Model suggest that climate change resulting from increasing greenhouse gas emissions would become considerably more pronounced if air quality were dramatically improved in the future. Specifically, the globally averaged surface air temperature and amount of precipitation could increase in less than a decade by $0.8 \mathrm{~K}$ and $3 \%$, respectively, if the entire amount of anthropogenic sulfate aerosols were removed from the atmosphere. The geographic patterns of the calculated changes bear resemblance with those found in greenhouse gas and aerosol scenario experiments (annual mean temperature increase of approximately $1 \mathrm{~K}$ on most continents, $4 \mathrm{~K}$ in the Arctic). This study suggests that possible future changes as well as the general issue of the stability of atmospheric aerosol loads should be considered in strategies aiming to maintain global warming below a prescribed threshold. It also underscores the need to account for associated possible changes in precipitation in such strategies. Citation: Brasseur, G. P., and E. Roeckner (2005), Impact of improved air quality on the future evolution of climate, Geophys. Res. Lett., 32, L23704, doi:10.1029/2005GL023902.

\section{Introduction}

[2] Past climate changes have been influenced by increasing atmospheric concentrations of greenhouse gases and by changes in the atmospheric aerosol load [Intergovernmental Panel on Climate Change (IPCC), 2001]. Coupled atmosphere-ocean models that account for the past evolution of the atmospheric composition (based on observational evidence) have simulated with some appreciable success the evolution of the globally averaged surface temperature of the Earth since the pre-industrial era [McAvaney et al., 2001]. The same models have been used to derive the expected response of the climate system to prescribed scenarios of the future atmospheric composition [Cubasch et al., 2001]. An important question is to assess more accurately the role of aerosols for the past and future climate evolutions. Aerosols perturb climate directly through interactions with shortwave solar light and terrestrial longwave radiation. Sulfate aerosols, for example, scatter back to space a fraction of the incoming solar energy, and hence produce a cooling of the Earth surface. Aerosols also affect climate indirectly by modifying the radiative properties and lifetime of the clouds, and probably by modifying the precipitation regimes and patterns [IPCC, 2001]. Fundamental work is needed to better quantify the role of microphysical processes affecting atmospheric aerosols and clouds. The degree by which aerosols have masked greenhouse-induced global warming is still under debate [see, e.g., Penner et al., 2001].

[3] The presence and the chemical nature of aerosols in the atmosphere have been modified as a result of human activities, and specifically of intense fossil fuel combustion. Coal burning, for example, is a major source of sulfate aerosols, while biomass burning and the use of diesel engines are major sources of black carbon. Air quality is severely degraded by the presence of such particles, and the strong reduction in visibility as well as the health problems generated by high concentrations of particle matters have called for mitigation strategies. The purpose of this paper is to assess the potential consequences for climate of a drastic reduction in the atmospheric aerosol load, and specifically in the concentration of sulfate aerosols.

\section{Methods}

[4] We use the Hamburg coupled atmosphere-ocean model, which includes the atmospheric ECHAM-5 general circulation model implemented at a T63 horizontal resolution with 31 levels in the vertical [Roeckner et al., 2003], and the ocean and sea ice MPI-OM model at a resolution of $1.5^{\circ}$ with 40 vertical levels [Marsland et al., 2003]. When integrated over a period of 500 years under pre-industrial (year 1860) conditions, this coupled system has been shown to provide a drift-free surface temperature in the absence of transient climate forcing. A small ensemble of three model simulations (with different initial conditions) was performed for each case considered in the present study, and all results are presented for the respective ensemble means. The model integrations start in 1860, and account for the radiative forcing caused by long-lived greenhouse gases $\left(\mathrm{CO}_{2}, \mathrm{CH}_{4}\right.$. $\mathrm{N}_{2} \mathrm{O}$, CFCs), ozone $\left(\mathrm{O}_{3}\right)$ and sulfate aerosols $\left(\mathrm{SO}_{4}\right)$. The direct aerosol effect is calculated by transforming the sulfate mass into number concentrations; this is performed by assuming a lognormal size distribution and taking into account the dependency of particle size on ambient relative humidity [Hess et al., 1998]. The first indirect (Twomey) effect is realized via empirical relationships between sulfate mass mixing ratio and cloud droplet number concentration [Boucher and Lohmann, 1995].

[5] The first part of the simulation attempts to reproduce the evolution of climate from year 1860 to year 2000 in response to prescribed changes in the atmospheric levels of greenhouse gases and sulfate aerosols (E. Roeckner et al., Impact of carbonaceous aerosol emissions on regional climate change, submitted to Climate Dynamics, 2005). The simulation is performed for prescribed varying concentrations of well-mixed greenhouse gases according to our best observational estimates. The time-varying concentrations of ozone and sulfate aerosols are specified according to pre-calculated values for prescribed emissions of precur- 

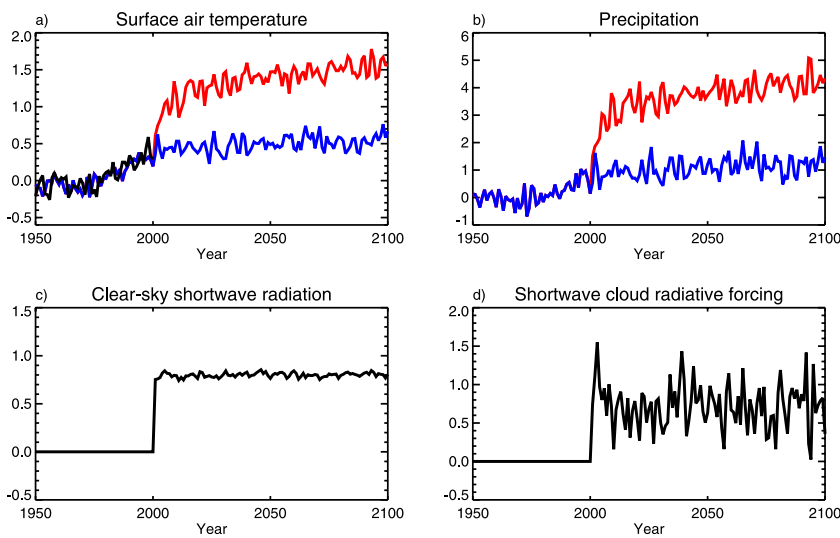

Figure 1. (a) Temporal evolution of global and annual mean surface air temperature anomalies $(\mathrm{K})$ with respect to the mean 1961-1990 in experiment A (blue), in experiment B (red), and in the observations (P. D. Jones et al., Global and hemispheric temperature anomalies 1856-2000-Land and marine instrumental records, 2001, available at http:// cdiac.ornl.gov/trends/temp/jonescru/jones.html). (b) As in Figure 1a but for precipitation anomalies (percent). (c) As in Figure 1a but for the difference (B-A) in top-of-atmosphere clear-sky shortwave radiation $\left(\mathrm{W} / \mathrm{m}^{2}\right)$. (d) As in Figure 1a but for the difference (B-A) in shortwave cloud radiative forcing $\left(\mathrm{W} / \mathrm{m}^{2}\right)$.

sor compounds [Kiehl et al., 1999; O. Boucher, personal communication, 2004]. In the specific case of sulfate, the anthropogenic emissions of sulfur are assumed to be roughly $2 \mathrm{Tg}$ in $1860,10 \mathrm{Tg}$ in 1900, $20 \mathrm{Tg}$ in 1920, $40 \mathrm{Tg}$ in 1960 , and $70 \mathrm{Tg}$ in year 2000. Other potential forcing mechanisms including solar variability and volcanic eruptions, and the effects of non-sulfate aerosols are ignored.

[6] For the period after year 2000, two idealized scenarios are considered. The goal of these simulations is not to present realistic scenarios in terms of future emissions, but to illustrate response time scales associated with the physics of the climate system. In the first of them, the atmospheric concentration of greenhouse gases and the sulfate aerosol load remain constant at their level of 2000 (experiment A or 'commitment' case). To a first approximation, this case describes a highly idealized situation in which the emissions of the long-lived greenhouse gases are becoming insignificant, while no significant actions are taken to reduce the emissions of aerosol precursors. In particular, it should be noted that the lifetimes of many radiative forcing agents currently contributing to global warming are long (including, e.g., carbon dioxide, which is the dominant warming agent and has a time scale for removal from the atmosphere of more than a hundred years even in the absence of emissions). The second case is similar, but, in addition, anthropogenic sulfate aerosols are assumed to be entirely removed from the atmosphere during the period following year 2000 (experiment B). In contrast to warming agents, the anthropogenic aerosols that act to mask the warming effect have very short lifetimes of a few days or weeks, due mainly to their removal in rainfall, so that changes in the global aerosol load will occur promptly if emissions are altered. This sensitivity experiment is intended to illustrate the character of responses to measures that may be taken to remove aerosol particles from the atmosphere. The difference between the two cases (B-A) is not intended to represent any realistic scenario, but indicates the maximum climate impact that might result from a substantial rapid improvement in air quality. Note, however, that the present study focuses on the role of anthropogenic sulfate aerosols, which are abundant in the industrialized regions of the Northern Hemisphere, but ignores the potentially important additional effects of black carbon and organic aerosol particles, which are released, for example, by wildfires, mostly in the tropics.

\section{Results and Discussion}

[7] The evolution of the globally averaged surface air temperature between years 1950 and 2100 , calculated by the climate model is represented by Figure 1a. The values are expressed in Kelvin as deviations from the respective mean temperatures over the 1961-1990 time-period. For the period preceding year 2000, the model reproduces with some success the observed global mean temperature change, and specifically the pronounced upward trend observed between 1980 and 2000. After year 2000, the two different scenarios $(\mathrm{A}, \mathrm{B})$ must be considered. In the case where the forcing is maintained at its current level (A, blue curve), the climate system evolves towards an equilibrium situation at a rate determined mainly by the ocean timescales. In the case where anthropogenic sulfate aerosols are abruptly removed from the atmosphere (B; red curve), the model predicts a rapid initial perturbation of the Earth's climate followed by a slow adjustment towards an equilibrium state. The global and annual mean surface air temperature increases by as much as $0.8 \mathrm{~K}$ within the first 5 years. By 2100, the temperature difference $(\mathrm{B}-\mathrm{A})$ reaches $1 \mathrm{~K}$, and the amount of precipitation has increased by $3 \%$ in the global, annual mean (Figure 1b).

[8] The rapid change in temperature can be attributed to the abrupt elimination of both the direct and the first indirect aerosol effect. The simulated top of the atmosphere (TOA) clear-sky sulfate forcing is about $-0.8 \mathrm{Wm}^{-2}$, as can be inferred from the difference in upward clear-sky fluxes at the top of the atmosphere and at the surface, respectively (Figure 1c). After year 2000, according to the experimental setup, it remains at this value in experiment $A$ and vanishes in experiment B. The difference pattern B-A (Figure 2a) shows pronounced anomalous shortwave heating of 5$8 \mathrm{Wm}^{-2}$ at TOA in the industrialized regions of the Northern Hemisphere (eastern US, Europe, East Asia). It is important to note that these numbers refer to clear-sky
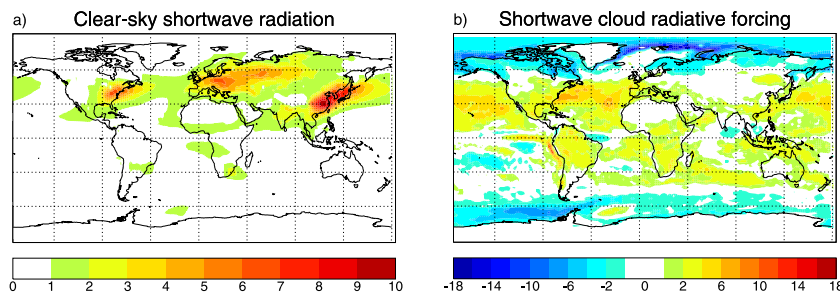

Figure 2. (a) Annual mean differences (B-A) in clear-sky top of the atmosphere shortwave radiation $\left(\mathrm{W} / \mathrm{m}^{2}\right)$ for the time period 2071-2100. (b) As in Figure 2a but for the difference in shortwave cloud radiative forcing $\left(\mathrm{W} / \mathrm{m}^{2}\right)$. 

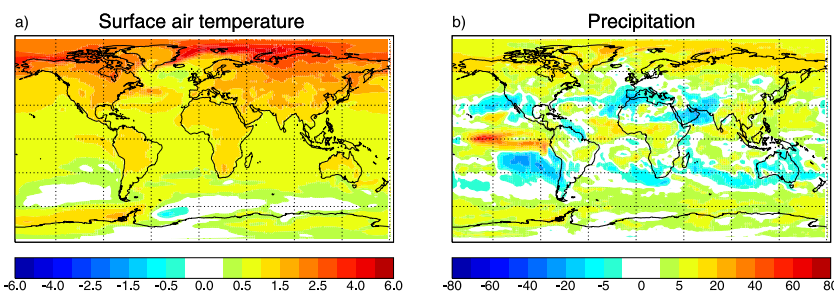

Figure 3. (a) Annual mean difference (B-A) in surface air temperature (K) for the time period 2071-2100. (b) As in Figure $3 \mathrm{a}$ but for the difference in precipitation (percent).

conditions, and that the all-sky direct radiative effect is systematically smaller.

[9] The cloud radiative forcing shown in Figure 1d involves changes in macrophysical cloud properties (e.g., fractional cover, water content), cloud microphysics (e.g., cloud droplet number concentration) and cloud optical properties, including the first indirect aerosol effect. In year 2001 the indirect effect is almost $-1 \mathrm{Wm}^{-2}$, which can be inferred from the difference B-A in the first year of the sensitivity experiments (2001). This falls in the range of previous estimates [Lohmann and Feichter, 2005], but the numerical values are subject to much wider uncertainties than the direct aerosol effect. The spatial distribution of the difference B-A in shortwave cloud forcing (Figure 2b) shows enhanced cloud reflection in experiment B at high latitudes. This is caused by additional cloud formation in areas where sea ice is melting $(-18 \%$ in the Northern Hemisphere and $-10 \%$ in the Southern Hemisphere). At lower latitudes, between about $40^{\circ} \mathrm{S}$ and $50^{\circ} \mathrm{N}$, the changes are generally positive, i.e., clouds are darker and less abundant in the 'cleaner' and warmer atmosphere. This is most evident over the North Atlantic and North Pacific but also over South America and Africa.

[10] When analyzing the annually averaged temperature patterns (Figure 3a), the differences B-A are most pronounced over the continents, where they are generally higher than $+1 \mathrm{~K}$ in both hemispheres. In large parts of the Arctic, they reach more than $+3 \mathrm{~K}$, specifically in northern Canada and northern Siberia (almost $5 \mathrm{~K}$ ). The high-latitude warming is most pronounced in boreal winter (not shown) with widespread temperature anomalies of more than $+5 \mathrm{~K}$ along the ice edge in the Atlantic sector of the Arctic. Over the tropical ocean, the changes are of the order of $0.5-1 \mathrm{~K}$, and are even smaller in the southern ocean and in the North Atlantic, where the strength of the thermohaline circulation decreases by about $20 \%$ at the end of the 21 st century. The temperature response as well as the annual mean change in precipitation (Figure $3 \mathrm{~b}$ ) bears some resemblance with those typically found in IPCC scenario experiments forced by increasing concentrations of both greenhouse gases and sulfate aerosols [e.g., Cubasch et al., 2001]. This suggests that the precipitation changes are largely driven by temperature changes in response to the removal of the aerosols. Precipitation is increasing by more than $5 \%$ at high northern latitudes and in most parts of the tropics whilst slight decreases are simulated over parts of the subtropics. A significant increase in precipitation (more than 50\%) is found in the eastern tropical Pacific, suggesting an El-Niño like change in the mean climate state of the tropical Pacific.

\section{Conclusions}

[11] Calculations performed with the Hamburg Climate model suggest that climate change resulting from increasing greenhouse gas emissions would become considerably more pronounced if air quality was dramatically improved in the future. If the entire load of anthropogenic sulfate aerosols was removed from the atmosphere, the globally averaged surface air temperature and precipitation amount would increase by approximately $0.8 \mathrm{~K}$ and $2 \%$, respectively, within less than a decade. The significant disturbances predicted to occur over the continents of the Northern Hemisphere (typically $1.5-2 \mathrm{~K}$ on an annual basis by the end of the 21st century) are attributed to the elimination of both the direct and indirect radiative effect of sulfate aerosol particles (roughly $-1.5 \mathrm{Wm}^{-2}$ in year 2000). The widespread surface warming of more than $3 \mathrm{~K}$ predicted in the Arctic results from the additional ice albedo feedback. This effect, however, is partly compensated by a cooling associated by additional evaporation and cloud formation due to the melting of sea ice in the course of the simulation. In other regions of the world, and specifically on the continents of the Southern Hemisphere, the changes in surface temperature and precipitation result from changes in the global atmospheric dynamics (teleconnections), with consequences in local cloud forcing.

[12] Finally, it should be stressed that this study has implications for environmental management strategies aimed at maintaining global warming below a specified threshold. The objective of Article 2 of the United Nations Framework Convention on Climate Change [United Nations, 1992] is 'to achieve stabilization of greenhouse gas concentrations in the atmosphere that would prevent dangerous anthropogenic interference with the climate system'. Here we have shown why such strategies must account not only for greenhouse gas emissions but also for the direct and indirect climate effects of aerosol particles if they are to be scientifically based. A reduction in the atmospheric aerosol load has become evident in certain regions of the world, with suggestive impacts on solar insolation at the surface [Pinker et al., 2005; Wild et al., 2005]. The atmospheric concentration of these particles could change substantially in the future in response to energy consumption and measures aimed at improving air quality. While the lifetimes and hence timescales of warming effects of many greenhouse gases extend for decades to centuries, the lifetimes of aerosols and related cooling terms are only a few day s or weeks. Thus, the balance between the two terms is not necessarily a stable one. Further, changes in aerosols have been shown here to have the potential to strongly influence precipitation. Thus, strategies to limit climate warming below a specified threshold need to be reconciled with strategies to reduce air pollution.

[13] Acknowledgments. The authors would like to thank S. Solomon for helpful suggestions regarding the present study, as well as M. Schultz and Ph. Stier for providing useful comments on the manuscript. This research was financed in part by the German Ministry for Education and Research (BMBF) under the DEKLIM Project and by the European 
Community under the ENSEMBLES Project. The simulations were performed on the NEC SX-6 supercomputer installed at the German Climate Computing Centre (DKRZ) in Hamburg.

\section{References}

Boucher, O., and U. Lohmann (1995), The sulfate-CCN-cloud albedo effect: A sensitivity study using two general circulation models, Tellus, Ser. $B, 47,281-300$.

Cubasch, U., et al. (2001), Projections of future climate change, in Climate Change 2001: The Scientific Basis-Third Assessment Report of the $I P C C$, pp. 525-582, Cambridge Univ. Press, New York.

Hess, M., P. Koepke, and I. Schult (1998), Optical properties of aerosols and clouds: The software package OPAC, Bull. Am. Meteorol. Soc., 79, $831-844$.

Intergovernmental Panel on Climate Change (2001), Climate Change 2001: The Scientific Basis-Third Assessment Report of the Intergovernmental Panel on Climate Change (IPCC), 944 pp., Cambridge Univ. Press, New York.

Kiehl, J. T., T. L. Schneider, R. W. Portmann, and S. Solomon (1999), Climate forcing due to tropospheric and stratospheric ozone, J. Geophys. Res., 104, 31,239-31,254.

Lohmann, U., and J. Feichter (2005), Global indirect aerosol effects: A review, Atmos. Chem. Phys., 5, 715-737.
Marsland, S. J., H. Haak, J. H. Jungclaus, M. Latif, and F. Röske (2003), The Max-Planck-Institute global ocean/sea ice model with orthogonal curvilinear coordinates, Ocean Modell., 5, 91-127.

McAvaney, B. J., et al. (2001), Model evaluation, in Climate Change 2001: The Scientific Basis-Third Assessment Report of the IPCC, pp. 471523, Cambridge Univ. Press, New York.

Penner, J. E., et al. (2001), Aerosols, their direct and indirect effects, in Climate Change 2001: The Scientific Basis-Third Assessment Report of the IPCC, pp. 289-416, Cambridge Univ. Press, New York.

Pinker, R. T., B. Zhang, and E. G. Dutton (2005), Do satellites detect trends in surface solar radiation?, Science, 308, 850-854.

Roeckner, E., et al. (2003), The atmospheric general circulation model ECHAM5. Part I: Model description, Rep. 349, 127 pp., Max Planck Institute for Meteorology, Hamburg, Germany.

Stern, D. I. (2005), Global sulfur emissions from 1850 to 2000, Chemosphere, 58(2), doi:10.1016/j.chemosphere.2004.08.022.

United Nations (1992), United Nations Framework Convention on Climate Change (UNFCCC), Bonn, Germany. (Available at http://www.unfccc.int/) Wild, M., et al. (2005), From dimming to brightening: Decadal changes in polar radiation at the Earth's surface, Science, 308, 847-850.

G. P. Brasseur and E. Roeckner, Max Planck Institute for Meteorology, D-20146 Hamburg, Germany. (brasseur@dkrz.de) 